\title{
Copy number variations associated with autism spectrum disorders contribute to a spectrum of neurodevelopmental disorders
}

\author{
Jill A. Rosenfeld, MS, Blake C. Ballif, PhD, Beth S. Torchia, PhD, Trilochan Sahoo, PhD, \\ J. Britt Ravnan, PhD, Roger Schultz, PhD, Allen Lamb, PhD, Bassem A. Bejjani, MD, \\ and Lisa G. Shaffer, PhD
}

\begin{abstract}
Purpose: Autism spectrum disorders represent a range of neurodevelopmental disorders that have been shown to have a strong genetic etiological component. Microarray-based comparative genomic hybridization and other molecular cytogenetic techniques are discovering an increasing number of copy number variations in individuals with autism spectrum disorder. Methods: We examined the yield of abnormal microarray-based comparative genomic hybridization findings in our laboratory for individuals referred for testing for autism spectrum disorder. We also examined the presence of autistic features among 151 additional individuals who were referred for microarray-based comparative genomic hybridization testing for indications other than autism spectrum disorder but had genomic alterations overlapping those found in cases referred for autism spectrum disorder. Results: We identified 1461 individuals referred for testing for autism spectrum disorder, with likely significant abnormalities reported in approximately $11.6 \%$ of individuals analyzed with whole-genome arrays. These abnormalities include alterations that encompass novel candidate genes such as SNTG2, SOX5, HFE, and TRIP38. A minority of individuals with overlapping abnormalities (19\%) had autistic features, and many of the copy number variations identified in our study are inherited (69\% among those found in individuals with autism spectrum disorder). Conclusions: Our results suggest these copy number variations are one of multiple factors contributing to the development of an autism spectrum disorder phenotype. Additionally, the broad phenotypic spectrum of the patients with these copy number variations suggests that these copy number variations are not autism spectrum disorder-specific but likely more generally impair neurodevelopment. Genet Med 2010:12(11):694-702.
\end{abstract}

Key Words: autism, ASD, microarray, $C N V$, neurodevelopment

A utism spectrum disorders (ASDs, OMIM 209850) describe range of behaviors that involve varying degrees of impaired language development, socialization, and interests. Individuals with autism, or autistic disorder, at the severe end of the spectrum, have findings before 3 years of age in three catego-

From Signature Genomic Laboratories, Spokane, Washington.

Lisa G. Shaffer, PhD, Signature Genomic Laboratories, 2820 N. Astor St, Spokane, WA 99207. E-mail: shaffer@signaturegenomics.com.

Disclosure: J.A. Rosenfeld, B.C. Ballif, B.S. Torchia, T. Sahoo, J.B. Ravnan, R. Schultz, A. Lamb, B.A. Bejjani and L.G. Shaffer are employees of Signature Genomics, a subsidiary of PerkinElmer.

Supplemental digital content is available for this article. Direct URL citations appear in the printed text and are provided in the HTML and PDF versions of this article on the journal's Web site (www.geneticsinmedicine.org).

Submitted for publication May 5, 2010.

Accepted for publication June 15, 2010.

Published online ahead of print August 30, 2010.

DOI: $10.1097 / G I M .0 b 013 e 3181 \mathrm{f0c5f3}$ ries: impaired reciprocal social interaction, impaired communication, and restricted, repetitive, or stereotyped behaviors. Individuals with Asperger syndrome have all characteristic impairments except for language deficits, manifesting before 3 years of age. For those with impairments in only two of the three categories or impairments manifesting after 3 years of age, a diagnosis of pervasive developmental delay (PDD) not otherwise specified is given. ${ }^{1}$ ASD is estimated to have an incidence of approximately $0.6 \%$ in the general population, although a recent study suggests the prevalence of ASD may be increasing, nearing $1 \% .^{2,3}$ ASD occurs more commonly in males, with a recent study demonstrating a 4.5:1 male-to-female ratio., ${ }^{2,3}$

The genetics of ASD are heterogeneous and not fully understood. Only $10-20 \%$ of individuals with ASD have a known etiology, which may include single-gene disorders and cytogenetic abnormalities. ${ }^{4}$ However, the heritability of autism is high, with twin studies yielding estimates of $90 \%$ or higher for the narrow phenotype of autism. ${ }^{5}$ This has prompted a search for susceptibility loci, with linkage studies and genome-wide screens yielding many candidates. Because of this large number of loci and the differences in monozygotic and dizygotic concordance rates, ASD is frequently considered to have a complex, multigenic etiology with environmental influence. ${ }^{6}$

A variety of cytogenetic abnormalities has been detected in patients with ASD, including rearrangements such as maternally derived duplications of the Prader-Willi/Angelman syndrome region on $15 \mathrm{q} 11 \mathrm{q} 13$, estimated to be present in $1 \%$ of ASD cases ${ }^{4,5,7}$; terminal deletions of $2 \mathrm{q}$ and $22 \mathrm{q}^{8}$; and deletions of $7 \mathrm{q} 31.5$ Smaller, novel deletions and duplications have been found in large-population studies of individuals with ASD using microarray-based comparative genomic hybridization (aCGH), ${ }^{9-13}$ including some recurrent abnormalities, such as the microdeletion and microduplication of $16 \mathrm{p} 11.2 .^{14-16}$ Detection rates for copy number variations (CNVs) in these large studies are $7.0-11.5 \%$ for detrimental abnormalities, ${ }^{9,12} 7-10 \%$ for de novo abnormalities in sporadic autism, ${ }^{14,17}$ and $11.6-12.5 \%$ for autism-specific abnormalities. ${ }^{10,11}$ This detection rate increases when looking at syndromic ASD (ASD cooccurring with other symptoms suggestive of a genetic syndrome), with one study showing a detection rate of $27.5 \% .^{13}$

Because of the finding of genomic imbalances in individuals with ASD, aCGH has been recommended as a first-tier test in the evaluation of patients with ASD, with the potential of having the highest yield of any single, clinically available test. 9,18 In this report, we examine the yield of abnormal aCGH findings in our laboratory for individuals referred for testing for ASD. Additionally, we survey the presence of autistic features in individuals with deletions and duplications overlapping those found in individuals with ASD to elucidate the spectrum of neurodevelopmental abnormalities associated with these CNVs. 


\section{MATERIALS AND METHODS}

\section{Bacterial artificial chromosome microarray analysis}

Microarray analysis was performed on some individuals in this cohort (Table 1) with a bacterial artificial chromosome (BAC) microarray (the SignatureChip ${ }^{\mathbb{B}}$; Signature Genomic Laboratories, Spokane, WA). The five versions of the microarray have increasing coverage of the genome, and the array version used was based on time of sample receipt. Version 1.0 was used from March 2004 until October 2004, Version 2.0 until October 2005, Version 3.0 until May 2006, Version 4.0 until November 2007, and the SignatureChip Whole Genome (SignatureChipWG) until December 2009. Array coverage was designed to target specific microdeletion/microduplication regions, subtelomeres, and pericentromeres. The more recent arrays have increasing inclusion of more microdeletion/microduplication regions and genes in important developmental pathways, with the WG array adding coverage to the spaces between targeted regions, with an average gap size between contigs of $\sim 1.6 \mathrm{Mb}$. A comparison of the contents of versions $1.0-\mathrm{WG}$ is available at: http://www.signaturegenomics.com/clone_list.html. Microarray analysis was performed as described. ${ }^{19,20}$ Results were visualized using our laboratory-developed computer software program Genoglyphix (available at: http://www.signature genomics.com/genoglyphix.html).

\section{Oligonucleotide aCGH}

Oligonucleotide-based microarray analysis was performed on some of the individuals reported in this cohort (Table 1) using a 105K-feature whole-genome microarray (SignatureChip Oligo Solution ${ }^{\mathrm{TM}}$, custom designed by Signature Genomic Laboratories, made by Agilent Technologies, Santa Clara, CA) as described previously. ${ }^{21}$ This oligonucleotide-based microarray was offered for clinical use beginning February 2008, and physicians have been given the option of using this array or the BAC-based microarray for their patients' samples since that time.

\section{Fluorescence in situ hybridization}

Abnormalities detected by aCGH were visualized by metaphase or interphase fluorescence in situ hybridization using one or more $\mathrm{BAC}$ clones determined to be abnormal by aCGH.22,23

\section{Subject identification}

We searched our database of more than 5,000 genomic abnormalities found in 22,680 samples submitted for clinical testing for CNVs in individuals with indications for study related to an ASD, including "autism," "autistic," "PDD," "pervasive" (developmental delay), and "Asperger" (syndrome). A genomic abnormality was considered potentially causative if it met at least one of the following criteria: (1) de novo in origin, (2) overlapping with another case in our database referred for ASD, (3) overlapping with autism-associated genes or loci reported in the literature, or (4) $>1 \mathrm{Mb}$ in size.

\section{Evaluation of cases with abnormalities overlapping those detected in individuals with ASD}

We pursued further analysis of some of the loci determined to potentially causative in the individuals with ASD, excluding abnormalities associated with a well-described syndrome and abnormalities of the sex chromosomes. All individuals with abnormalities of the same copy number state (i.e., gain or loss) overlapping these autosomal loci were identified in our database. Clinicians were asked to supply information about the presence or absence of ASD for all cases with overlapping abnormalities, with the exception of individuals younger than 15 months, who were too young to be evaluated for ASD. Information about how a diagnosis of ASD was made was not obtained.

\section{RESULTS}

\section{Genomic abnormalities in individuals referred for ASD}

Between March 2004 and July 2008, 22,680 samples were submitted for clinical testing. Of these, 1,461 had an ASD as an indication for study. Abnormalities were reported in 180 $(12.3 \%)$ of these cases. The rate of abnormalities reported was higher with whole-genome arrays (16.8\% for the BAC microarray and $23.5 \%$ for the oligonucleotide microarray) compared with $8.6 \%$ for Versions $1-4$ of the targeted BAC microarray (Table 1). Based on the criteria stated earlier in the text, the abnormalities in 113 of these cases were determined to be potentially causative, yielding a detection rate of $7.7 \%$ among

Table 1 Frequency of abnormalities found by different microarray platforms

\begin{tabular}{|c|c|c|c|c|c|c|}
\hline & $\begin{array}{c}\text { Targeted BAC array } \\
\text { version } 1-4\end{array}$ & $\begin{array}{l}\text { Whole-genome } \\
\text { BAC array }\end{array}$ & $\begin{array}{l}\text { Whole-genome } \\
\text { oligonucleotide }\end{array}$ & Total & $\begin{array}{l}P \text { (targeted } \\
\text { vs. whole } \\
\text { genome) }\end{array}$ & $\begin{array}{l}P \text { (whole-genome } \\
\text { BAC vs. } \\
\text { oligonucleotide) }\end{array}$ \\
\hline Total cases analyzed & 15,467 & 5,422 & 1,791 & 22,680 & & \\
\hline $\begin{array}{l}\text { Number of cases with ASD } \\
\text { indication for study }\end{array}$ & 881 & 482 & 98 & 1,461 & & \\
\hline $\begin{array}{l}\text { Number of ASD cases with } \\
\text { abnormality reported }\end{array}$ & 76 & 81 & 23 & 180 & $1.3 \times 10^{-7}$ & 0.15 \\
\hline Abnormality rate & $8.6 \%$ & $16.8 \%$ & $23.5 \%$ & $12.3 \%$ & & \\
\hline $\begin{array}{l}\text { Number of ASD cases with } \\
\text { potentially causative } \\
\text { abnormality }^{a}\end{array}$ & 46 & 54 & 13 & 113 & $9.4 \times 10^{-6}$ & 0.60 \\
\hline $\begin{array}{l}\text { Rate of potentially causative } \\
\text { abnormalities }\end{array}$ & $5.2 \%$ & $11.2 \%$ & $13.3 \%$ & $7.7 \%$ & & \\
\hline
\end{tabular}


all cases referred for ASD (Table 1). Detection rates of these abnormalities were not significantly different between the BAC and oligonucleotide whole-genome arrays $(P=0.60$, two-tailed Fisher's exact test), but detection rates were significantly greater in the whole-genome arrays compared with earlier targeted BAC array Versions $1-4\left(P=9.4 \times 10^{-6}\right.$, one-tailed Fisher's exact test). The abnormalities found in the remaining 67 cases referred for ASD did not meet criteria for potentially causative abnormalities (Table, Supplemental Digital Content 1, http://links.lww.com/GIM/A122).

Of the 113 cases with potentially causative abnormalities (Table, Supplemental Digital Content 2, http://links.lww.com/GIM/A123), 34 abnormalities were associated with syndromes that have been well reported and associated with ASD, and these were excluded from the second part of the study in which autistic features were assessed in cases with overlapping abnormalities. Also excluded were the 16 cases with abnormalities considered to be potentially causative on the $\mathrm{X}$ or $\mathrm{Y}$ chromosome, leaving 63 cases with abnormalities in 41 distinct autosomal regions in which to investigate ASD features in cases with overlapping abnormalities.

\section{ASD in individuals with genomic alterations in autosomal loci of interest}

Information about ASD or autistic features was obtained for 151 individuals with overlapping abnormalities and without an ASD indication for study, 29 of whom (19\%) were found to have autistic features or an ASD diagnosis (Table, Supplemental Digital Content 3, http://links.lww.com/GIM/A118). The altered genomic regions of all cases with autistic features were compared to determine the smallest region of overlap of their abnormalities, some of which overlapped with previous reports of CNVs found in ASD or included genes that have been associated with ASD (Table 2). The CNVs surveyed were mostly inherited (41/59, or $69 \%$, among autistic individuals, and $42 / 68$, or $62 \%$, among nonautistic individuals).

\section{DISCUSSION}

Our survey of potentially causative CNVs detected in a series of 1461 individuals referred for aCGH testing because of an ASD or autistic features allows for a broader view of the contribution of these CNVs to neurodevelopmental disorders. For CNVs at most of these loci, autistic features were only present in a subset of individuals, indicating these genomic gains and losses are likely one of multiple factors contributing to features of ASD. This phenotypic variability may also be indicative of a more general contribution of the CNVs to a range of neurodevelopmental disturbances, and other factors likely influence the ultimate phenotypic penetrance and expressivity. These CNVs may affect biological pathways that generally impact neurodevelopment and manifest themselves phenotypically as developmental delays, mental retardation (MR), ASD, or other neuropsychiatric disorders. Our survey also identified CNVs not previously reported in association with ASD. Although the gene content of some of these novel CNVs is compelling, we have a limited number of cases in our study, so further research is required to determine their pathogenicity.

Our results demonstrate CNVs at loci associated with ASD do not always result in autistic features. These data also support previous studies of recurrent microdeletions and microduplications, such as those at $15 \mathrm{q} 13.3^{24-29}$ and at the distal region of $1 \mathrm{q} 21.1,30,31$ in which autistic features are present in only a subset of cases. Although formal ASD evaluations were not performed for all patients in the study, we were able to ascertain that some patients' neurobehavioral profiles clearly did not raise clinical suspicion of an ASD. For example, patients found to have the $15 \mathrm{q} 13.3$ microdeletion who did not have autistic features instead had developmental delays, seizures, language difficulties, and other behavioral issues such as attention-deficit hyperactive disorder. In addition, some of these CNVs may be inherited from an apparently normal parent, $29,30,32,33$ which further suggests these CNVs are not always associated with neurodevelopmental impairments; they demonstrate reduced penetrance and variable expressivity. Therefore, it is difficult to predict whether an individual with one of these CNVs will develop autistic features, another neurodevelopmental disorder, or neither, particularly in prenatal or asymptomatic cases.

Some of the CNVs identified in this study overlap with those found in cohorts of patients with other neurodevelopmental disorders, further broadening the phenotypic spectra associated with these CNVs. For example, CNVs within DPP6 and CNTNAP2, for which our study has one duplication and two deletions, respectively, in autistic individuals, have also been associated with schizophrenia and attention-deficit hyperactive disorder without being present in a control population. ${ }^{34} \mathrm{CNVs}$ in schizophrenia cohorts have included duplications of $7 \mathrm{q} 36.1$ and 9p24.235; our study has one and two individuals, respectively, with these duplications and autistic features. Microdeletions of $15 q 13.3$ have been significantly associated with schizophrenia, ${ }^{36,37}$ and we have seven individuals in our study with this deletion and autistic features. Our laboratory has identified a 16 p12.2 microdeletion in a patient referred for schizophrenia (Sahoo et al., in preparation) in addition to three in this study with autistic features. ASD is frequently comorbid with MR, and ASD is occasionally identified in individuals with genetic syndromes not typically associated with ASD, similar to three cases in this cohort referred for ASD who had the Williams syndrome microdeletion at 7q11.2. This MR-ASD comorbidity may be because individuals with reduced mental capacity cannot compensate for social impairments caused by other genetic or environmental factors ${ }^{38}$ or because MR and the cognitive and social/behavioral impairments in ASD share common physiological pathways. ${ }^{39,40}$ The phenotypic spectra associated with these various $\mathrm{CNV}$ s suggest that these genomic alterations likely contribute to abnormal neurodevelopment, but other factors, both genetic and environmental, may be needed to contribute to the development of an ASD or other specific phenotype. This overlap between causes of ASD and other neurodevelopmental disorders implicates an increasing number of potential genetic causes for ASD, and the causes likely differ from one case to the next, complicating the identification of any single factor.

The CNVs surveyed in our study include some with a novel association with ASD, although further study of these genes and replication in other cohorts will be necessary to determine whether this association with ASD is significant. The CNVs include a de novo deletion of SOX5 (OMIM 604975), a transcription factor shown to play roles in chondroblast function and oligodendrocyte differentiation and migration; a de novo deletion of $H F E$, mutations of which are associated with the autosomal-recessive $H F E$-associated hereditary hemochromatosis (OMIM 235200), TRIP38, whose function is unknown, and multiple histone genes at $6 \mathrm{p} 22.1$; and a maternally inherited deletion of SNTG2 (OMIM 608715), which encodes a scaffolding protein shown to interact with neuroligins implicated in autism. ${ }^{41}$ This deletion involving part of SNTG2 in a patient with autistic features was inherited from a mother with a mild personality disorder and was absent in a normal brother. As these are only single cases, further studies in other populations 


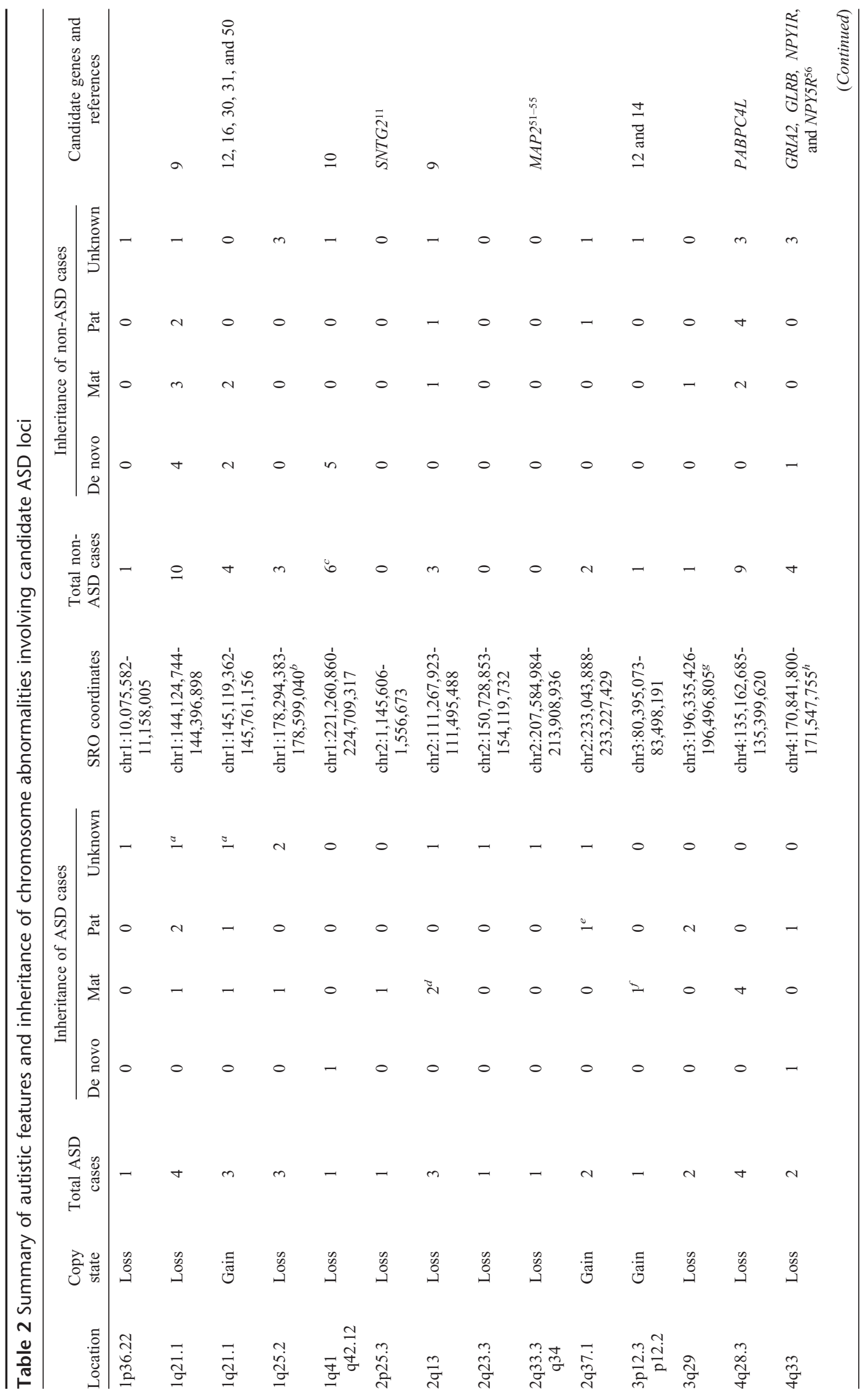




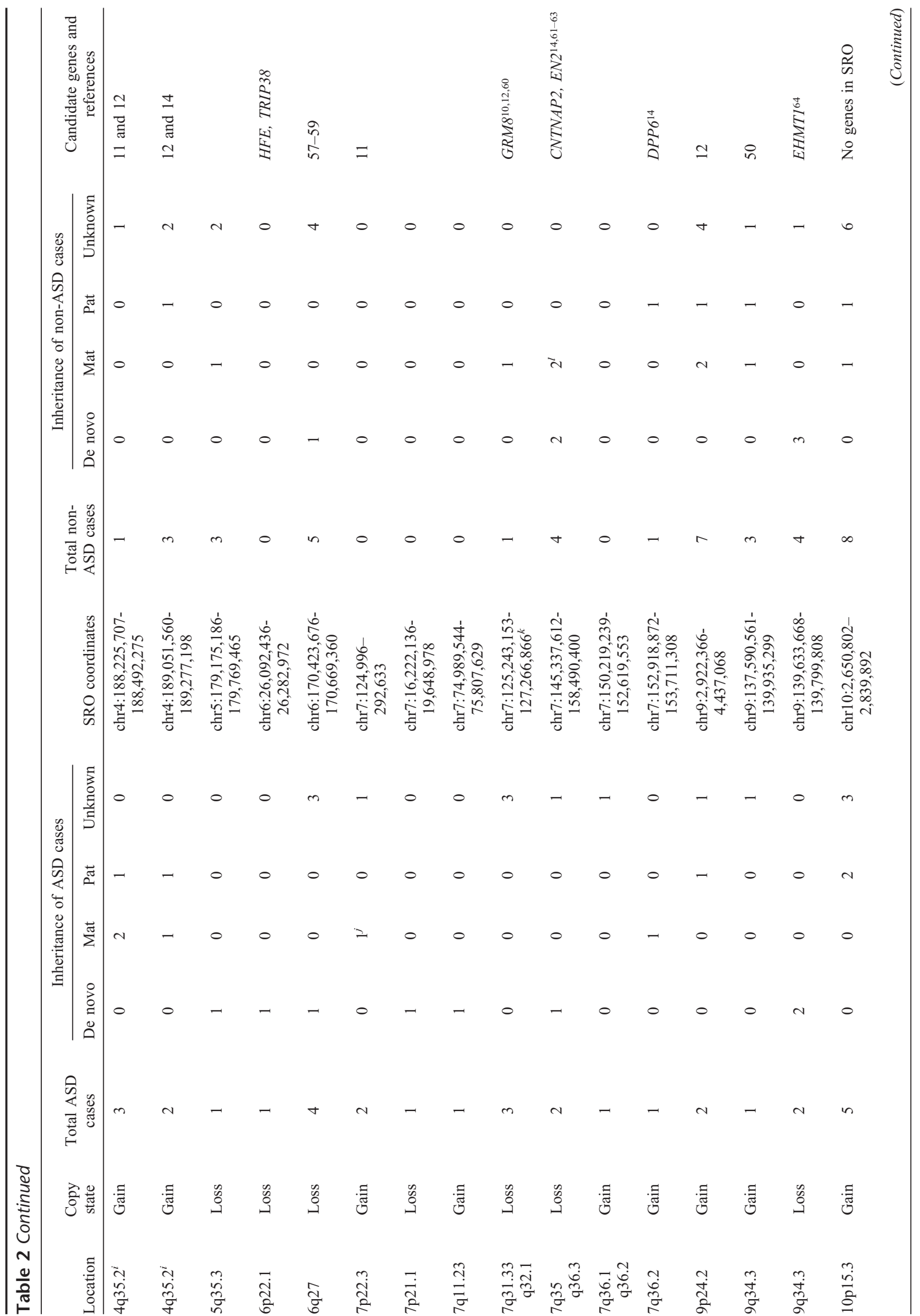




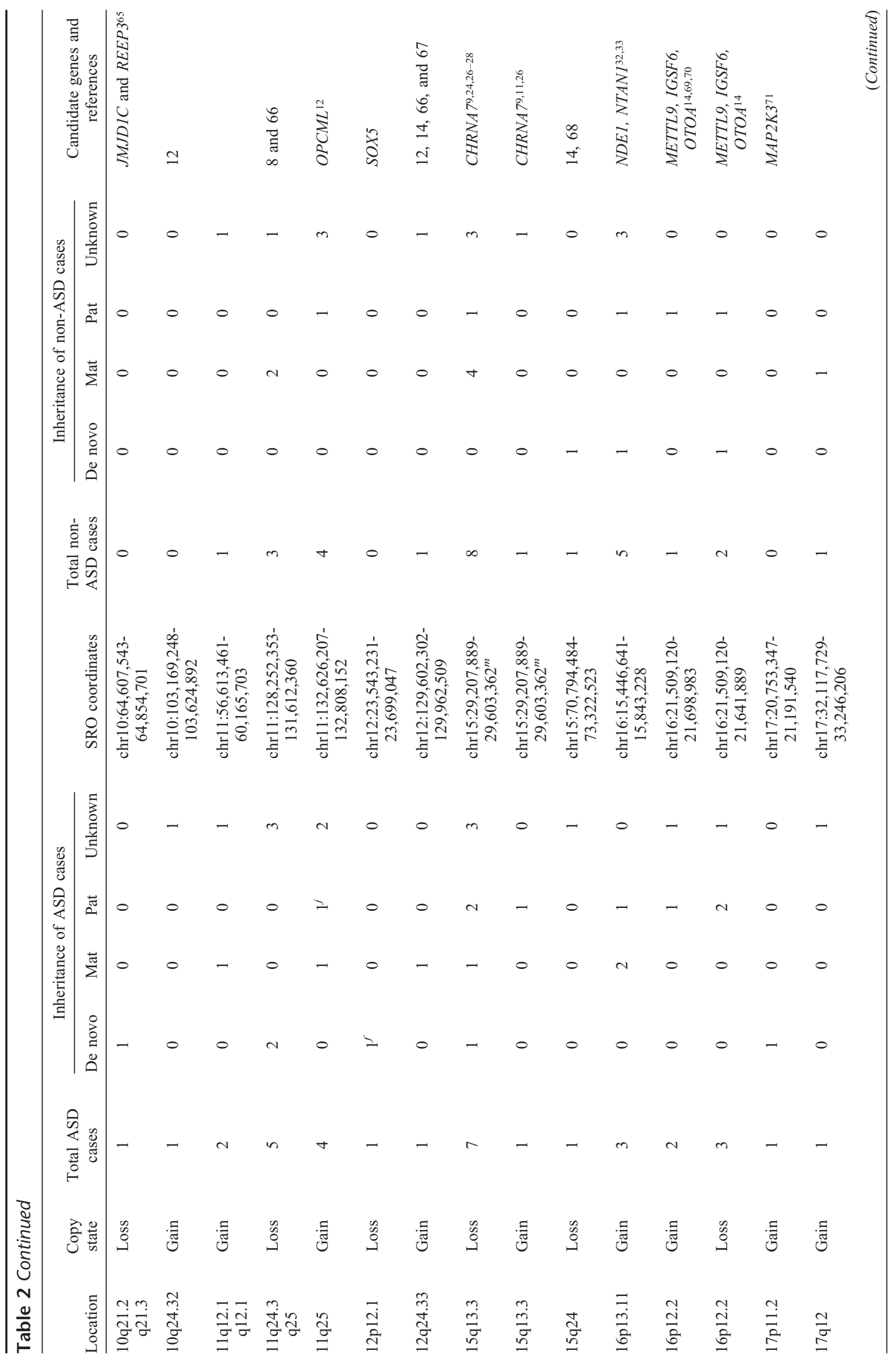




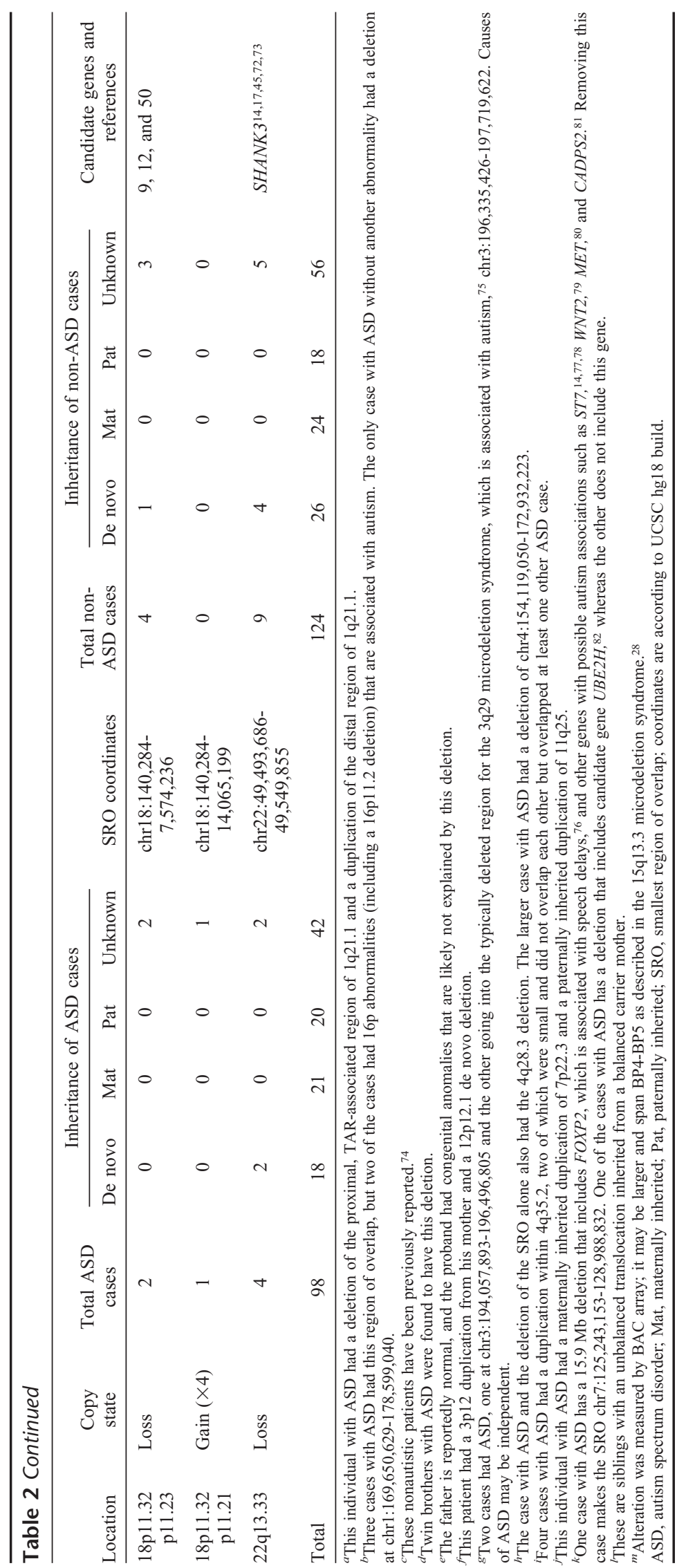


may confirm this association with autism, show a more general association with neurodevelopmental disorders, as we have shown with other CNVs in this survey, or may show the CNVs to be likely benign.

We also identified a recurrent microdeletion and microduplication at $16 \mathrm{p} 12.2$, although population data suggest these recurrent CNVs may not be clinically significant. This microdeletion has been identified in controls (20/6712), ${ }^{83}$ and the frequency is not significantly different than either the frequency among cases referred to our laboratory for clinical aCGH testing $(33 / 16,773)$ or among the subset of these cases referred for an ASD (2/580). This microduplication had a frequency of $14 / 6,712$ in the same control population, ${ }^{83}$ which is not significantly different than the frequency in cases referred for aCGH testing $(22 / 16,773)$ or the subset of cases being tested for ASD (1/580). This example illustrates a potential limitation to this study, as truly benign variants may be identified and in the absence of control data may be difficult to implicate or reject as candidates. Conversely, some of the CNVs that are not categorized as potentially causative may be rare loci that predispose to ASD, as the criteria used in this study are a screening tool and may eliminate some smaller or inherited abnormalities that have a legitimate connection with ASD. Larger, independent studies are required to identify and replicate the association between any specific CNV and ASD.

Despite the studies that suggest high heritability for autism and, therefore, a strong genetic contribution, the interaction between genetic factors and ASD is not fully understood. Because of the absence of common genetic factors in individuals with ASD, and as a result of an analysis of family history data, a multigenic model is the commonly accepted model for ASD. ${ }^{42}$ If ASD is truly multigenic then a CNV could be one of several genetic factors required to lead to ASD. These CNVs could be in normal individuals in the population and, therefore, may be unrecognized in studies of de novo abnormalities or "autismspecific" changes. It is possible that some of the small, recurrent, inherited abnormalities in this cohort, such as the $4 \mathrm{q} 28.3$ microdeletion or the $16 \mathrm{p} 12.2$ microdeletion and microduplication, could represent one of these common CNVs that can contribute to ASD when other unknown factors are present. The paucity of obvious results in all these searches for common CNVs in ASD suggests that the contributory factors are varied, so it may be rare to find multiple families with the same abnormalities.

An increasing number of microdeletions and microduplications are being reported in association with ASD, and the nature of the association between the CNV and ASD, whether it is causative, contributory, or potentially benign, is slowly being elucidated. Although some genomic disorders have been associated with a specific neurobehavioral profile, ${ }^{43-45}$ and the relative contribution that other CNVs, such as 16p11.2 microdeletions and microduplications, to ASD is being described, ${ }^{11,14,16,46,47}$ the roles, if any, that most CNVs play in ASD etiology have not been defined. Some of these CNVs are implicated in disease, even when inherited from a normal parent, ${ }^{24,30}$ a paradigmatic shift from traditional cytogenetic orthodoxy. ${ }^{32,48,49}$ Furthermore, these CNVs may be present in individuals with a spectrum of neurodevelopmental impairments, which suggests they play a general role in altering brain development. In any individual with ASD, multiple, varied factors, one of which may be a $\mathrm{CNV}$, likely contribute to the phenotype.

\section{REFERENCES}

1. American Psychiatric Association. Diagnostic and statistical manual of mental disorders: DSM-IV-TR, 4th ed., text revision ed. Washington, DC: American Psychiatric Association, 2000.

2. Fombonne E. Epidemiology of autistic disorder and other pervasive developmental disorders. J Clin Psychiatry 2005;66(suppl 10):3-8.

3. Autism and Developmental Disabilities Monitoring Network Surveillance Year 2006 Principal Investigators; Centers for Disease Control and Prevention (CDC). Prevalence of autism spectrum disorders-Autism and Developmental Disabilities Monitoring Network, United States, 2006. MMWR Surveill Summ 2009;58:1-20.

4. Abrahams BS, Geschwind DH. Advances in autism genetics: on the threshold of a new neurobiology. Nat Rev Genet 2008;9:341-355.

5. Freitag CM. The genetics of autistic disorders and its clinical relevance: a review of the literature. Mol Psychiatry 2007;12:2-22

6. Zhao X, Leotta A, Kustanovich V, et al. A unified genetic theory for sporadic and inherited autism. Proc Natl Acad Sci USA 2007;104:12831-12836.

7. Xu J, Zwaigenbaum L, Szatmari P, Scherer SW. Molecular cytogenetics of autism. Curr Genomics 2004;5:347-364.

8. Vorstman JA, Staal WG, van Daalen E, van Engeland H, Hochstenbach PF, Franke L. Identification of novel autism candidate regions through analysis of reported cytogenetic abnormalities associated with autism. Mol Psychiatry 2006;11:1, 18-28.

9. Shen Y, Dies KA, Holm IA, et al. Clinical genetic testing for patients with autism spectrum disorders. Pediatrics 2010;125:e727-e735.

10. Cusco I, Medrano A, Gener B, et al. Autism-specific copy number variants further implicate the phosphatidylinositol signaling pathway and the glutamatergic synapse in the etiology of the disorder. Hum Mol Genet 2009;18: 1795-1804.

11. Christian SL, Brune CW, Sudi J, et al. Novel submicroscopic chromosomal abnormalities detected in autism spectrum disorder. Biol Psychiatry 2008; 63:1111-1117

12. Szatmari P, Paterson AD, Zwaigenbaum L, et al. Mapping autism risk loci using genetic linkage and chromosomal rearrangements. Nat Genet 2007; 39:319-328.

13. Jacquemont ML, Sanlaville D, Redon R, et al. Array-based comparative genomic hybridisation identifies high frequency of cryptic chromosomal rearrangements in patients with syndromic autism spectrum disorders. J Med Genet 2006;43:843-849.

14. Marshall CR, Noor A, Vincent JB, et al. Structural variation of chromosomes in autism spectrum disorder. Am J Hum Genet 2008;82:477-488.

15. Kumar RA, KaraMohamed S, Sudi J, et al. Recurrent 16p11.2 microdeletions in autism. Hum Mol Genet 2008;17:628-638.

16. Weiss LA, Shen Y, Korn JM, et al. Association between microdeletion and microduplication at 16p11.2 and autism. N Engl J Med 2008;358:667-675.

17. Sebat J, Lakshmi B, Malhotra D, et al. Strong association of de novo copy number mutations with autism. Science 2007;316:445-449.

18. Schaefer GB, Mendelsohn NJ. Clinical genetics evaluation in identifying the etiology of autism spectrum disorders. Genet Med 2008;10:301-305.

19. Ballif BC, Theisen A, Coppinger J, et al. Expanding the clinical phenotype of the 3q29 microdeletion syndrome and characterization of the reciprocal microduplication. Mol Cytogenet 2008;1:8.

20. Bejjani BA, Saleki R, Ballif BC, et al. Use of targeted array-based CGH for the clinical diagnosis of chromosomal imbalance: is less more? Am J Med Genet A 2005;134:259-267.

21. Ballif BC, Theisen A, McDonald-McGinn DM, et al. Identification of a previously unrecognized microdeletion syndrome of $16 \mathrm{q} 11.2 \mathrm{q} 12.2$. Clin Genet 2008;74:469-475.

22. Shaffer LG, McCaskill C, Han JY, et al. Molecular characterization of de novo secondary trisomy 13. Am J Hum Genet 1994;55:968-974.

23. Traylor RN, Fan Z, Hudson B, et al. Microdeletion of $6 q 16.1$ encompassing EPHA7 in a child with mild neurological abnormalities and dysmorphic features: case report. Mol Cytogenet 2009;2:17.

24. Ben-Shachar S, Lanpher B, German JR, et al. Microdeletion 15q13.3: a locus with incomplete penetrance for autism, mental retardation, and psychiatric disorders. J Med Genet 2009;46:382-388.

25. Helbig I, Mefford HC, Sharp AJ, et al. 15q13.3 microdeletions increase risk of idiopathic generalized epilepsy. Nat Genet 2009;41:160-162.

26. Miller DT, Shen Y, Weiss LA, et al. Microdeletion/duplication at $15 \mathrm{q} 13.2 \mathrm{q} 13.3$ among individuals with features of autism and other neuropsychiatric disorders. J Med Genet 2009;46:242-248.

27. Pagnamenta AT, Wing K, Akha ES, et al. A 15q13.3 microdeletion segregating with autism. Eur J Hum Genet 2009;17:687-692.

28. Sharp AJ, Mefford HC, Li K, et al. A recurrent $15 \mathrm{q} 13.3$ microdeletion syndrome associated with mental retardation and seizures. Nat Genet 2008; 40:322-328

29. van Bon BW, Mefford HC, Menten B, et al. Further delineation of the $15 \mathrm{q} 13$ microdeletion and duplication syndromes: a clinical spectrum varying from non-pathogenic to a severe outcome. J Med Genet 2009;46:511-523.

30. Mefford HC, Sharp AJ, Baker C, et al. Recurrent rearrangements of chro- 
mosome 1q21.1 and variable pediatric phenotypes. $N$ Engl J Med 2008;359: 1685-1699.

31. Brunetti-Pierri N, Berg JS, Scaglia F, et al. Recurrent reciprocal 1q21.1 deletions and duplications associated with microcephaly or macrocephaly and developmental and behavioral abnormalities. Nat Genet 2008;40:1466-1471.

32. Hannes FD, Sharp AJ, Mefford HC, et al. Recurrent reciprocal deletions and duplications of $16 \mathrm{p} 13.11$ : the deletion is a risk factor for MR/MCA while the duplication may be a rare benign variant. J Med Genet 2009;46:223-232.

33. Ullmann R, Turner G, Kirchhoff M, et al. Array CGH identifies reciprocal 16 p13.1 duplications and deletions that predispose to autism and/or mental retardation. Hum Mutat 2007;28:674-682.

34. Elia J, Gai X, Xie HM, et al. Rare structural variants found in attentiondeficit hyperactivity disorder are preferentially associated with neurodevelopmental genes. Mol Psychiatry 2010;15:637-646.

35. Walsh T, McClellan JM, McCarthy SE, et al. Rare structural variants disrupt multiple genes in neurodevelopmental pathways in schizophrenia. Science 2008;320:539-543.

36. Rare chromosomal deletions and duplications increase risk of schizophrenia. Nature 2008;455:237-241.

37. Stefansson H, Rujescu D, Cichon S, et al. Large recurrent microdeletions associated with schizophrenia. Nature 2008;455:232-236.

38. Skuse DH. Rethinking the nature of genetic vulnerability to autistic spectrum disorders. Trends Genet 2007;23:387-395.

39. O'Donovan MC, Kirov G, Owen MJ. Phenotypic variations on the theme of CNVs. Nat Genet 2008;40:1392-1393.

40. Cohen D, Pichard N, Tordjman S, et al. Specific genetic disorders and autism: clinical contribution towards their identification. J Autism Dev Disord 2005;35:103-116.

41. Yamakawa H, Oyama S, Mitsuhashi H, et al. Neuroligins 3 and $4 X$ interact with syntrophin-gamma2, and the interactions are affected by autism-related mutations. Biochem Biophys Res Commun 2007;355:41-46.

42. Folstein SE, Rosen-Sheidley B. Genetics of autism: complex aetiology for a heterogeneous disorder. Nat Rev Genet 2001;2:943-955.

43. Lewandowski KE, Shashi V, Berry PM, Kwapil TR. Schizophrenic-like neurocognitive deficits in children and adolescents with 22q11 deletion syndrome. Am J Med Genet B Neuropsychiatr Genet 2007;144B:27-36.

44. Coldren CD, Lai Z, Shragg P, et al. Chromosomal microarray mapping suggests a role for BSX and Neurogranin in neurocognitive and behavioral defects in the $11 \mathrm{q}$ terminal deletion disorder (Jacobsen syndrome). Neurogenetics 2009;10:89-95.

45. Philippe A, Boddaert N, Vaivre-Douret L, et al. Neurobehavioral profile and brain imaging study of the 22q13.3 deletion syndrome in childhood. Pediatrics 2008;122:e376-e382.

46. Rosenfeld JA, Coppinger J, Bejjani BA, et al. Speech delays and behavioral problems are the predominant features in individuals with developmental delays and 16p11.2 microdeletions and microduplications. $J$ Neurodevelop Disord 2010;2:26-38.

47. Bijlsma EK, Gijsbers AC, Schuurs-Hoeijmakers JH, et al. Extending the phenotype of recurrent rearrangements of $16 \mathrm{p} 11.2$ : deletions in mentally retarded patients without autism and in normal individuals. Eur J Med Genet 2009;52:77-87.

48. Mefford HC. Genotype to phenotype-discovery and characterization of novel genomic disorders in a "genotype-first" era. Genet Med 2009;11:836-842.

49. Sharp AJ. Emerging themes and new challenges in defining the role of structural variation in human disease. Hum Mutat 2009;30:135-144.

50. Bucan M, Abrahams BS, Wang K, et al. Genome-wide analyses of exonic copy number variants in a family-based study point to novel autism susceptibility genes. PLoS Genet 2009;5:e1000536.

51. Bisgaard AM, Kirchhoff M, Tumer Z, et al. Additional chromosomal abnormalities in patients with a previously detected abnormal karyotype, mental retardation, and dysmorphic features. Am J Med Genet A 2006;140: 2180-2187.

52. Brandau DT, Lund M, Cooley LD, Sanger WG, Butler MG. Autistic and dysmorphic features associated with a submicroscopic 2q33.3-q34 interstitial deletion detected by array comparative genomic hybridization. Am J Med Genet A 2008;146A:521-524

53. Van Buggenhout G, Van Ravenswaaij-Arts C, Mc Maas N, et al. The $\operatorname{del}(2)(\mathrm{q} 32.2 \mathrm{q} 33)$ deletion syndrome defined by clinical and molecular characterization of four patients. Eur J Med Genet 2005;48:276-289.

54. Mukaetova-Ladinska EB, Arnold H, Jaros E, Perry R, Perry E. Depletion of MAP2 expression and laminar cytoarchitectonic changes in dorsolateral prefrontal cortex in adult autistic individuals. Neuropathol Appl Neurobiol 2004;30:615-623.

55. Pescucci C, Meloni I, Bruttini M, et al. Chromosome 2 deletion encompassing the MAP2 gene in a patient with autism and Rett-like features. Clin Genet 2003;64:497-501.

56. Ramanathan S, Woodroffe A, Flodman PL, et al. A case of autism with an interstitial deletion on $4 \mathrm{q}$ leading to hemizygosity for genes encoding for glutamine and glycine neurotransmitter receptor sub-units (AMPA 2, GLRA3, GLRB) and neuropeptide receptors NPY1R, NPY5R. BMC Med Genet 2004;5:10.
57. Anderlid BM, Schoumans J, Anneren G, et al. Subtelomeric rearrangements detected in patients with idiopathic mental retardation. Am J Med Genet 2002;107:275-284.

58. Batanian JR, Hussain MI. An unbalanced half-cryptic translocation involving the $6 \mathrm{q}$ subtelomeric region and $2 \mathrm{p} 25.3$ in a child with mental retardation: uses and limitations of fluorescence in situ hybridization. Clin Genet 1999; 55:265-268.

59. Eash D, Waggoner D, Chung J, Stevenson D, Martin CL. Calibration of 6q subtelomere deletions to define genotype/phenotype correlations. Clin Genet 2005;67:396-403.

60. Serajee FJ, Zhong H, Nabi R, Huq AH. The metabotropic glutamate receptor 8 gene at 7q31: partial duplication and possible association with autism. J Med Genet 2003;40:e42.

61. Alarcon M, Abrahams BS, Stone JL, et al. Linkage, association, and geneexpression analyses identify CNTNAP2 as an autism-susceptibility gene. Am J Hum Genet 2008:82:150-159.

62. Arking DE, Cutler DJ, Brune CW, et al. A common genetic variant in the neurexin superfamily member CNTNAP2 increases familial risk of autism. Am J Hum Genet 2008:82:160-164.

63. Bakkaloglu B, O'Roak BJ, Louvi A, et al. Molecular cytogenetic analysis and resequencing of contactin associated protein-like 2 in autism spectrum disorders. Am J Hum Genet 2008;82:165-173.

64. Stewart DR, Kleefstra T. The chromosome 9q subtelomere deletion syndrome. Am J Med Genet C Semin Med Genet 2007;145C:383-392.

65. Castermans D, Vermeesch JR, Fryns JP, et al. Identification and characterization of the TRIP8 and REEP3 genes on chromosome 10q21.3 as novel candidate genes for autism. Eur J Hum Genet 2007;15:422-431.

66. Lukusa T, Holvoet M, Vermeesch JR, Devriendt K, Fryns JP. Partial monosomy $11 \mathrm{q}$ and trisomy $12 \mathrm{q}$ : variable expression in two siblings. Genet Couns 2003;14:155-164.

67. Rodriguez L, Martinez Guardia N, Herens C, et al. Subtle trisomy 12q24.3 and subtle monosomy 22q13.3: three new cases and review. Am J Med Genet A 2003;122A:119-124

68. Sharp AJ, Selzer RR, Veltman JA, et al. Characterization of a recurrent 15q24 microdeletion syndrome. Hum Mol Genet 2007;16:567-572.

69. Finelli P, Natacci F, Bonati MT, et al. FISH characterisation of an identical (16)(p11.2p12.2) tandem duplication in two unrelated patients with autistic behaviour. J Med Genet 2004:41:e90.

70. Behjati F, Shafaghati Y, Firouzabadi SG, et al. M-banding characterization of a $16 \mathrm{p} 11.2 \mathrm{p} 13.1$ tandem duplication in a child with autism, neurodevelopmental delay and dysmorphism. Eur J Med Genet 2008;51:608-614.

71. Kogan JM, Miller E, Ware SM. High resolution SNP based microarray mapping of mosaic supernumerary marker chromosomes 13 and 17: delineating novel loci for apraxia. Am J Med Genet A 2009;149A:887-893.

72. Durand CM, Betancur C, Boeckers TM, et al. Mutations in the gene encoding the synaptic scaffolding protein SHANK3 are associated with autism spectrum disorders. Nat Genet 2007;39:25-27.

73. Moessner R, Marshall CR, Sutcliffe JS, et al. Contribution of SHANK3 mutations to autism spectrum disorder. Am J Hum Genet 2007;81:12891297

74. Shaffer LG, Theisen A, Bejjani BA, et al. The discovery of microdeletion syndromes in the post-genomic era: review of the methodology and characterization of a new 1q41q42 microdeletion syndrome. Genet Med 2007; 9:607-616.

75. Willatt L, Cox J, Barber J, et al. 3q29 microdeletion syndrome: clinical and molecular characterization of a new syndrome. Am J Hum Genet 2005;77: 154-160.

76. Lennon PA, Cooper ML, Peiffer DA, et al. Deletion of 7q31.1 supports involvement of FOXP2 in language impairment: clinical report and review. Am J Med Genet A 2007;143A:791-798.

77. Vincent JB, Herbrick JA, Gurling HM, Bolton PF, Roberts W, Scherer SW. Identification of a novel gene on chromosome $7 \mathrm{q} 31$ that is interrupted by a translocation breakpoint in an autistic individual. Am J Hum Genet 2000; 67:510-514

78. Vincent JB, Petek E, Thevarkunnel S, et al. The RAY1/ST7 tumor-suppressor locus on chromosome $7 \mathrm{q} 31$ represents a complex multi-transcript system. Genomics 2002;80:283-294.

79. Wassink TH, Piven J, Vieland VJ, et al. Evidence supporting WNT2 as an autism susceptibility gene. Am J Med Genet 2001;105:406-413.

80. Campbell DB, Sutcliffe JS, Ebert PJ, et al. A genetic variant that disrupts MET transcription is associated with autism. Proc Natl Acad Sci USA $2006 ; 103: 16834-16839$

81. Sadakata T, Washida M, Iwayama Y, et al. Autistic-like phenotypes in Cadps2-knockout mice and aberrant CADPS2 splicing in autistic patients. $J$ Clin Invest 2007;117:931-943.

82. Vourc'h P, Martin I, Bonnet-Brilhault F, et al. Mutation screening and association study of the UBE2H gene on chromosome $7 \mathrm{q} 32$ in autistic disorder. Psychiatr Genet 2003;13:221-225.

83. Antonacci F, Kidd JM, Marques-Bonet T, Teague B, Ventura M, Girirajan $\mathrm{S}$, et al. Dynamic evolution and complex human genome polymorphism at 16p12.1 underlies microdeletion disease risk. Nat Genet (in press) 